\title{
Soberanía del bando y producción de nuda vida: Colombia como paradigma ejemplar
}

\section{Sovereignty of the bando and production of nuda vida: Colombia as an exemplary paradigm}

\author{
Adriana María Ruiz Gutiérrez. \\ Abogada y magíster en Filosofía Contemporánea por la Universidad de Antioquia - Medellin: doctora en Derecho por \\ la Universidad Santo Tomás - Bogotá; docente de la Facultad de Derecho de la Universidad de San Buenaventura- \\ Medellin, Facultad de Derecho de la Universidad Pontificia Bolivariana-Medellin, Colombia \\ Correo electrónico: adrianamaruiz@gmail.com
}

Con profunda gratitud a Sonia Atehortúa por el coraje de su verdad

\section{Resumen}

Las lecciones de la historia política occidental y, más particularmente, en América Latina, parecen mostrar que los acontecimientos políticos se encuentran regidos ineludiblemente por la guerra, el poder, la exclusión y, por supuesto, por la emergencia de numerosas figuras de autoridad armadas de violencia, quienes aparecen con mayor o menor frecuencia e intensidad en momentos de crisis institucional bajo la promesa de salvaguardar el orden y proteger la vida de los ciudadanos. En este sentido, la represión y la expansión de la violencia por parte de la autoridad soberana constituye, al igual que el estado de naturaleza hobbesiano, una amenaza permanente para quienes la padecen, ya que la lógica de la autoridad consiste en el incremento de los medios de poder, el abuso, la destrucción y, en consecuencia, una incesante configuración de enemigos, oposiciones y luchas. El desconocimiento de estos efectos en el discurso moderno respecto al derecho y la vida humana implica, en consecuencia, entrar en la lógica de la guerra y permanecer en ella hasta la aniquilación de amplias masas de seres humanos, por cuanto se exige, bien por ignorancia, bien por comodidad, la presencia ilimitada e indefinida del aparato de Estado y la autoridad soberana, quien ha de combatir a los enemigos cada vez más, menos familiares, cotidianos y sustituibles, haciendo uso de la vida y el cuerpo de los propios ciudadanos. De este modo, la guerra y el orden llevan hasta el extremo la violencia, cada vez más degradada e insólita, sacrificando libertades y numerosas vidas humanas bajo la muerte, la exclusión, el abandono.

Palabras clave: Soberanía del bando, nuda vida, Colombia, guerra, enemigo, abandono.

\begin{abstract}
The lessons of Western political history and, more particularly, of Latin America seem to show that political events are inevitably ruled by war, power, exclusion and, of course, by the emergence of numerous figures of authority armed with Violence, who appear with greater or less frequency and intensity in times of institutional crisis under the promise of safeguarding order and protecting the lives of citizens. In this sense, the repression and expansion of violence by the sovereign authority, like the Hobbesian state of nature, constitutes a permanent threat for those who suffer it, since the logic of authority consists in the increase of Means of power, abuse, destruction and, consequently, an incessant configuration of enemies, oppositions and struggles. The ignorance of these effects in the modern discourse with respect to the law and human life implies, consequently, to enter in the logic of the war and to remain in her until the annihilation of ample masses of human beings, since it is demanded, either by ignorance, Or for convenience, the unlimited and indefinite presence of the State apparatus and sovereign authority, who must combat enemies who are increasingly less familiar, everyday and substitutable, making use of the life and body of the citizens themselves. In this way, war and order carry to the extreme the ever more degraded and unusual violence, sacrificing freedoms and numerous human lives under death, exclusion, abandonment.
\end{abstract}

Keywords: Sovereignty of the gang, nuda vida, Colombia, war, enemy, abandonment. 


\section{Résumé}

Les leçons de l'histoire politique occidentale et, plus particulièrement, en Amérique latine, semblent montrer que les événements politiques sont régis inévitablement par la guerre, le pouvoir, l'exclusion et, bien sûr, par l'émergence de nombreuses figures d'autorité armés violence, qui apparaissent avec une fréquence et de l'intensité en période de crise institutionnelle variable sous la promesse de sauvegarder l'ordre et de protéger la vie des citoyens. En ce sens, la répression et l'expansion de la violence par l'autorité souveraine, il est, comme l'état de nature hobbesien, un permanent pour ceux qui souffrent menace, puisque la logique de l'autorité est l'augmentation des moyens de pouvoir, l'abus, la destruction et, par conséquent, un réglage des ennemis implacables, les oppositions et les luttes. L'ignorance de ces effets dans le discours moderne sur la vie droite et humaine implique, par conséquent, entrer dans la logique de la guerre et il y reste jusqu'à ce que l'anéantissement des masses d'êtres humains, au besoin, soit par l'ignorance soit pour la commodité, la présence illimitée et indéfinie de l'appareil d'Etat et l'autorité souveraine, qui doit combattre les ennemis de plus en plus moins familiers, tous les jours et remplaçables, faisant usage de la vie et le corps des citoyens. Ainsi, la guerre et pour conduire à la fin de la violence de plus en plus dégradé et inhabituel, sacrifier des libertés et de nombreuses vies dans la mort, l'exclusion, l'abandon.

Mots-clés: côté souveraineté, la vie nue, la Colombie, la guerre, l`ennemi, l>abandon. 


\section{Soberanía del bando y producción de nuda vida: Colombia como paradigma ejemplar*}

Adriana María Ruiz Gutiérrez

\section{INTRODUCCIÓN}

La relación entre la víctima potencial y la víctima actual no debe ser definida en términos de culpabilidad e inocencia. No hay nada que "expiar". La sociedad intenta desviar hacia una víctima relativamente indiferente, una víctima "sacrificable", una violencia que amenaza con herir a sus propios miembros, los que ella pretende proteger a cualquier precio. Todas las características que hacen terrorífica la violencia, su ciega brutalidad, la absurdidad de sus desenfrenos, no carecen de contrapartida: coinciden con su extraña propensión a arrojarse sobre unas víctimas de recambio, permiten engañar a esta enemiga y arrojarle, en el momento propicio, la ridícula presa que le satisfará. Los cuentos de hadas que nos muestran el lobo, al ogro o al ladrón engullendo vorazmente un gran pedrusco en lugar del niño que deseaban, podrían muy bien tener un carácter sacrificial (Girard, 1983, p. 12).

La nuta vita ha dejado en Colombia de ser una idea, para tomar cuerpo en esta "muchedumbre desnuda", en este cuerpo vivo de millones de desterrados, mujeres y hombres, campesinos y trabajadores, que a causa de la violencia militar y paramilitar han perdido sus tierras y su terruño. Por efecto de las acciones de esas fuerzas muchas poblaciones del campo colombiano se han convertido en pueblos fantasmas a la manera de La Comala de Juan Rulfo, llenos de polvo y de voces de muertos. Descuartizamientos de campesinos vivos, el sadismo de las ejecuciones, las violaciones, los cuerpos insepultos arrojados en fosas comunes, toda una anatomía y espectáculo de terror marcan los testimonios tanto de quienes presenciaron las masacres como de quienes las perpetraron (Anrup, 2012, p. 90).

El presente artículo es producto del proyecto: Derecho y Violencia. Código: 449011.16.P.05. Grupo de Investigación Derecho, Cultura y Ciudad. Línea de Investigación: Derecho Público. Universidad San Buenaventura - Medellín. 
En Colombia no hay exploración del otro cuando se manipula su cuerpo y se desgarra su carne. Quienes así actúan, no enfrentan dilemas morales porque lo hacen desde una posición en la cual ha quedado momentáneamente suspendida su identidad. Debido a ello, nada de lo que lesionan los perpetradores de las masacres es, a sus ojos, humano. Los muertos, esos otros que fueron vecinos y conocidos durante La Violencia y que hoy en día son unos extraños, no tienen esa calidad. Por lo tanto, no hay degradación ni deshumanización sistemática pues ante los asesinos sólo está presente la animalidad del otro. Sin embargo, ese otro que tienen delante de sí los asesinos, es una persona que grita e implora que no la maten, una persona que en medio de la parálisis que le produce el terror, apela al sentido humanitario de quien la va a asesinar. Pero quien ejecuta la masacre sólo tiene ante sí a un extraño que no pertenece a su mundo, un extraño que es el arquetipo de lo indecible, tal y como lo describe Bauman, físicamente cercano pero espiritualmente distante. La alteridad de las víctimas ha desaparecido para dar paso a unos extraños que no pertenecen al mundo de los aniquiladores (Uribe, 2004, pp. 134-135).

Jean-Luc Nancy (1940) utiliza la noción de bando, para explicar, la entrega de los individuos a la autoridad y, más específicamente, a sus mandatos, órdenes y decisiones sobre la guerra y la paz. Naturalmente, toda puesta en bando, o más precisamente, bajo el mandato de la persona representativa moderna implica, al mismo tiempo, despojar a la vida de toda su potencialidad y su justicia, reduciéndola a una mera vida, nuda vida o sobrevida, hasta lograr, finalmente, y con una extraordinaria facilidad, su anulación, sometimiento y destrucción. Aquí, la expresión nuda vida sirve para significar "al portador del nexo entre violencia y derecho que define la estructura de la soberanía, esto es, para identificar al ciudadano occidental que padece la violencia del Estado" (Galindo, 2005, p. 44; Castro, 2008, p. 55). En este punto, lo que debe entenderse es, precisamente, que la autoridad impone la violencia sobre los individuos, no solo con el fin de preservar el orden, sino también de reducir la vida a su mera naturalidad, en aras de exponerla a cada instante, sin ningún reparo, ni vacilación. Y, porque las teorías jurídico políticas modernas insisten en exponer o abandonar la vida humana a la decisión de la autoridad soberana y, por consiguiente, a una violencia sin precedentes que se manifiesta en las formas más banales, es que la violencia detentada por todos los hombres en el estado de naturaleza no desaparece bajo la promesa de pacificación estatal, sino que tan solo cambia de rostro en las históricas figuras de autoridad. La puesta en bando implica más que nunca la presencia de una persona representativa con capacidad suficiente para mantener la vida en su mera naturalidad y, en consecuencia, con voluntad suficiente para decidir sobre la destrucción de esta. La violencia de la autoridad soberana como medio de mantenimiento del derecho y el Estado se ha convertido, pues, en algo inaudito. Porque de modo tan sorprendente como paradojal, aquel que emplea la violencia como medio de conservación de la estructura jurídico-institucional respecto a 
las amenazas de la guerra siempre por venir y a los enemigos siempre móviles y sustituibles, concluye la escena bélica en el asesinato, la desaparición, el destierro de cientos de hombres, haciendo posible la inminente aparición de un Estado suicida.

Colombia constituye un paradigma ejemplar de la soberanía del bando, en la cual cientos de hombres, mujeres, soldados, campesinos, indígenas, negros, estudiantes, trabajadores, revolucionarios han sido expuestos a los excesos de la autoridad en el uso de la violencia para conservar al gran Leviatán que, por lo demás, terminó devorándose a sus propios hijos. En Colombia, la autoridad ha sido consustancial a su devenir histórico-político, ya sea en razón de sus permanentes crisis de institucionalidad, las cuales han ocasionado, a su vez, la declaratoria de múltiples estados de guerra y de excepción con miras a conservar la existencia del aparato estatal, ya sea en razón de la prolongación y la degradación de la guerra, la cual ha dejado de ser un hecho meramente circunstancial para convertirse en algo estructural y temporalmente indeterminado. No obstante, la violencia desagregada en la vida social y la multiplicidad de enemigos, cada vez, menos familiares, sumada a la inexistencia y la fragilidad de un orden jurídico-institucional, insuficiente para conjurar las tensiones políticas, la hostilidad y las agresiones bélicas, la comunidad política continúa reclamando la existencia de una autoridad que permita asegurar la vida e integridad de sus miembros. Y, a su vez, y por las mismas razones históricas, las múltiples autoridades representativas del orden han justificado el uso del poder y la violencia en la resolución de las causas del conflicto social y armado, así como en el sometimiento de los enemigos internos a la legalidad, con miras a garantizar no solo la vigencia del derecho y el Estado, sino también, y, al mismo tiempo, la vida e integridad de los ciudadanos. De manera que, tanto la comunidad política, como la institución estatal, han concebido la existencia de una autoridad fuerte y poderosa como la única vía para controlar el territorio, pacificar a la población que lo habita, monopolizar la violencia y los recursos bélicos, definir el enemigo y decidir sobre los medios de confrontación, declarar la guerra y el estado de excepción, es decir, la suspensión del derecho con miras a garantizar su vigencia (Uribe, 2005, p. 272).

$\mathrm{Y}$, al igual que en la práctica moderna, en Colombia continúa vigente el principio según el cual la guerra y la violencia constituyen los medios de creación y conservación del orden jurídico-institucional, así como los medios de destrucción más radicales de la vida humana. Porque cada uno de los representantes actualiza el pacto con los ciudadanos, en virtud del cual, la seguridad exige la obediencia a las armas y las leyes, pero, en ningún caso, la autoridad respaldada con sus amplios dispositivos de represión, ha logrado resolver el conflicto y, por lo tanto, edificar y conservar un orden eficaz que asegure la vida física de los individuos. Al contrario, la aparición de distintas figuras de autoridad en la historia del país solo ha exacerbado los dispositivos jurídicos y políticos, incluida la violencia, sobre la vida de los individuos, al punto de eliminar amplias masas de colombianos. Porque mientras subsista la guerra y, por lo tanto, la autoridad soberana, el sacrificio de cientos de hombres y de mujeres será cada vez más continuo y progresivo: "Lo que muchas veces se olvida es que si bien 
los regímenes democráticos tienen como precondición la soberanía, la construcción histórica de ella tiene que ver con la democracia y muchísima relación con la violencia y la sangre derramada" (Uribe, 2005, p. 272). Estas premisas prácticas y, al mismo tiempo, teóricas, permiten considerar, por supuesto, la existencia de una modernidad permanente en el país, tanto en sus reclamos de un Leviatán omnipotente que garantice la vida y la seguridad, como en la admisión de una autoridad que encarne la violencia plena del orden con miras a proteger el derecho y el Estado.

He aquí la paradoja: el Estado y, particularmente, el derecho requieren de una autoridad, esto es, de un quien decida sobre los medios de violencia y su ejecución con miras a garantizar su existencia, duración y eficacia, pero dicho mantenimiento ha dependido históricamente de la muerte de cientos de colombianos, quienes han sido, por lo demás, excepcionados o vencidos por generaciones. El derecho no puede operar eficazmente bajo condiciones de anormalidad, a menos, por supuesto, que normalice y legalice a cada instante lo inaudito: las batallas, el destierro, la desaparición, la tortura, las masacres, las violaciones. Y, pese a la confianza en la modernidad y, sobre todo, en su promesa de pacificación mediante la violencia que funda y mantiene el derecho y el Estado, María Teresa Uribe afirma que:

los totalitarismos, los fascismos, las dictaduras militares del Tercer Mundo están ahí para poner de manifiesto los peligros que para los ciudadanos entraña refugiarse en la jaula del león, pues el Leviatán enérgico y protector con el que soñaba Hobbes, bien puede convertirse en un monstruo que devora a sus enemigos, pero también a sus amigos (2005, p. 275).

A lo largo de la historia colombiana, el Jefe de Estado, el Gobierno y las fuerzas armadas no solo han suspendido e, incluso, modificado reiteradamente la Constitución Política que pretexta conservar mediante los prolongados estados de excepción, haciendo depender el orden jurídico-constitucional de su voluntad, sino que también ha ensayado distintas formas de violencia: desaparición, tortura, encarcelamiento, masacres, asesinatos selectivos, reclutamiento, detenciones arbitrarias, colaboración con la parainstitucionalidad, entre otros, bajo los argumentos de establecer las condiciones de existencia y normalidad requeridos por el orden jurídico-político. A diferencia de María Teresa Uribe y otros analistas políticos, quienes conciben que la

debilidad endémica de la soberanía como ausencia de Estado, pero, más que de omnipresencia, el Estado Nacional ha carecido de omnipotencia para tomar la decisión soberana [lo que devela] el fracaso en el uso de las armas y de la fuerza para restaurar el orden institucional a través de un Leviatán omnipotente (Uribe, 2005, p. 275).

Debe entenderse aquí que la autoridad siempre ha decidido bien sea por acción, bien sea por omisión sobre la vida de cientos de individuos.

En efecto, la autoridad, no solo ha definido y combatido a sus distintos enemigos políticos, quienes han disputado históricamente el monopolio de las armas, los territorios, la población y las normas, sino que también ha abandonado a centenares 
de hombres y mujeres, cuyas vidas, expuestas a la muerte han sido, posteriormente, arrebatadas por distintas agrupaciones armadas, sin ningún miramiento ni vacilación por parte del Estado colombiano. La figura de la autoridad es, por lo tanto, una categoría esencial para entender el derecho en su relación con la política y, más particularmente, con la guerra, así como para comprender la mortalidad del orden jurídico-estatal colombiano y, aún más, las abrumadoras dimensiones de la violencia en el país ejercidas por las distintas autoridades. Los peligros del Leviatán y, por ende, de la autoridad que lo anima, lo amplifica y lo perfecciona tanto en tiempos de paz, como en tiempos de guerra es, pues, innegable, y no solo desde un punto de vista teórico, sino también, y más que nada, histórico. Y, bajo esta perspectiva, Colombia constituye el mejor ejemplo de la letalidad de la violencia ejercida por la autoridad en nombre del Estado y el derecho en orden a garantizar la seguridad institucional mediante distintas formas, a saber: el abandono, la enemistad absoluta y la guerra permanente.

\section{ABANDONO}

Colombia ha presenciado durante más de cincuenta años de conflictos y violencias, distintas alianzas y rupturas políticas entre frentes guerrilleros, paramilitares, narcotráfico, aparato de Estado. Asimismo, han proliferado marchas de campesinos, desplazados, madres de desaparecidos, madres de soldados prisioneros, desempleados organizados, mercenarios rasos y profesionales que militan en ejércitos vandálicos. También se han sucedido mesas de negociación orientadas a la desmovilización, desarme y reintegración, al asesinato metódico y seriados de los desmovilizados, así como el eterno retorno de los guerreros a la lucha bajo distintas formas y diversos roles. Y mientras se narra la infinita historia de la guerra y el desarme, la fundación y la aniquilación total de los grupos armados y sus víctimas, es necesario insistir en las preguntas del filósofo colombiano Ernesto Hernández (2003, p. 74): ¿Cómo hemos llegado hasta aquí? (pregunta ética); ¿Desde cuándo resistimos a lo intolerable? (pregunta histórica); ¿En qué condiciones estamos aquí? (pregunta política). La sociedad colombiana ha preferido, la servidumbre del olvido y la comodidad a la autonomía del pensar libre y responsablemente el estado actual de la violencia y sus efectos en las formas de vida comunitarias. La sociedad se ha negado indiferentemente a la comprensión de aquellos fenómenos de autoridad, poder, opresión y abandono de la vida humana que, en cambio, parece aceptar sin más: ¿Cómo es posible, entonces, afirmar la democracia si pervive en "nosotros" y entre "nosotros" la típica medida totalitaria del olvido y la negación indiferente de los demás? ¿Cómo afirmar la vida humana en nuestros regímenes jurídico-políticos cuando las vidas de algunos se evaporan en las formas más continuas y radicales de eliminación? Porque la reducción de la vida justa a una mera vida natural, esto es, a una vida evaporada de humanidad comienza incluso antes su destrucción física. Y, aquí se produce, justamente, la insoportable eficacia de la crueldad, esto es, en la 
deshumanización antes de toda destrucción. La desgracia de los sobrevivientes causa horror cuando se la observa con atención, esto es, cuando aparecen desnudas, como algo que destruye efectivamente a los hombres.

Porque no solo la representación de cientos de cadáveres, heridos, torturados o mutilados causa horror y conmoción en el alma y el intelecto, sino, también, la profusa masa de hombres y mujeres cuyos esfuerzos consisten día a día en preservar su humanidad, aquello que constituye lo suyo: nombres, recuerdos, palabras, imágenes. Allí la muerte también aparece desnuda, no vestida. La clásica oposición entre el hombre y el animal aristotélica es sustituida ahora por la diferencia contemporánea entre el hombre y el no-hombre, el hombre y el cadáver que deambulan cotidianamente por las ciudades bajo el rostro de los desterrados, refugiados, humillados, empobrecidos, así como de los llamados desechables, gamines, indigentes, NN. El despojo de la humanidad constituye el dispositivo esencial de toda dominación totalitaria, por cuanto tiene ahí su principio y su finalidad. Y toda resistencia contra la opresión del olvido y la indiferencia de los demás se nutre de la fuerza subversiva del sufrimiento de los muertos y los desaparecidos, y también de los sobrevivientes (Metz, 1979, p. 121). En su trabajo Antropología de la inhumanidad. Un ensayo interpretativo sobre el terror en Colombia, María Victoria Uribe afirma que:

El mayor horror del siglo XX tiene que ver con esa pelea desesperada que libran hombres, mujeres y niños por sobrevivir en ambientes que los empujan cada vez más hacia una muerte que no guarda ninguna relación con sus vidas cotidianas. Son personas indefensas que poco pueden hacer por evitar lo que les va a suceder pues el enemigo que las acecha es silencioso, implacable e-impredecible (2004, pp. 16-17).

Y es, precisamente, porque la nuda vida del homo sacer y el musulmán supera los campos de concentración alemanes y sus dispositivos de aniquilación total, y porque se la encuentra ya abandonada en los espacios colectivos y los fenómenos del desarraigo, desaparición, exclusión, es que el hombre se debate únicamente en la mera sobrevivencia biológica: ya no basta, pues, en sobrevivirle a los rigores de la naturaleza, sino también a las organizaciones guerreras, incluyendo al Estado y su abandono. El estado de naturaleza se ha convertido, pues, en un estado de exclusión permanente donde las víctimas sacrificiales son expuestas a cada instante al fragor de las armas y la nimiedad de la sobrevida. Y así como la autoridad incrementa la violencia de la gran máquina sacrificial, asimismo, aumenta el número de cadáveres y la producción de sobrevivientes ahora abandonados en las metrópolis amnésicas y ensimismadas en la indiferencia social. Pero la puesta en bando supone algo más que matar el cuerpo, pues implica una sobreexposición a la pobreza, el hambre, el frío, es decir, a la precariedad más cruenta y absoluta. Porque la violencia sacrificial no es objetiva, únicamente, en la mutilación o la eliminación directa del cuerpo, sino también, en la suspensión de la nuda vida de aquellos hombres porosos que pueden ser muertos por cualquiera en virtud de la negación y la indiferencia. Aquí la vida se disuelve mediante la fragmentación, la extrañeza y, finalmente, la desaparición: La 
puesta en bando implica, inexorablemente, la destrucción total del ser abandonando o expuesto a la decisión de la autoridad y su violencia guerrera:

Pero la destrucción sólo es completa cuando ha hecho desparecer los últimos vestigios y no queda nada, absolutamente nada, que revele la existencia anterior de los objetos destruidos. La destrucción total quiere aprisionar las cosas, tanto su sustancia material como sus significados (Sofsky, 2006, p. 195).

No basta, entonces, la violencia del combate para matar los cuerpos, sino también la violencia sobre la vida misma, esto es, sobre la carne y el espíritu del hombre. De suerte que la aniquilación total no aparece únicamente en las batallas, el derramamiento de sangre, los cuerpos mutilados, el ruido de las armas, el destello de las bombas, sino también, y más precisamente, en la marginalidad de cientos de sobrevivientes empobrecidos, hacinados, abandonados al agotamiento y la desaparición. La vida es sagrada por su propia inmanencia y, en modo alguno, por la trascendencia respecto a Dios o el Estado. De ahí que "se destruye lo sagrado al profanarlo, ultrajarlo, mancillarlo, ensuciarlo” (Sofsky, 2006, p. 196). Es preciso, entonces, liberar a la vida de todo exceso de autoridad, poder y, por lo tanto, de violencia. En este sentido, bastan las cifras de letalidad para justificar toda crítica a la fuerza como medio de protección del Estado y el derecho en Colombia. Según el Centro Nacional de Memoria Histórica:

De acuerdo con la investigación del GMH [Grupo de Memoria Histórica], entre 1985 y 2012, murieron 40.787 combatientes. Es así como al compendiar estas cifras, es posible afirmar que el conflicto armado colombiano ha provocado aproximadamente 220.000 muertos. De estas muertes el $81,5 \%$ corresponde a civiles y el $18,5 \%$ a combatientes; es decir que aproximadamente ocho de cada diez muertos han sido civiles, y que, por lo tanto, son - ellos personas no combatientes, según el Derecho Internacional Humanitario — los más afectados por la violencia [...] Por otra parte, la violencia del conflicto armado tiene una dimensión no letal que acarrea consecuencias igualmente gravemente. Al 31 de marzo del 2013, el RUV [Registro Único de Víctimas] reportó 25.007 desaparecidos, 1.754 víctimas de violencia, sexual, 6.421 niños, niñas y adolescentes reclutados por grupos armados, y 4.744 .046 personas desplazadas. El trabajo de Cifras \& Conceptos para el GMH reporta 27.023 secuestros asociados con el conflicto armado entre 1970 y 2010, mientras que el Programa Presidencial de Atención Integral contra Minas Antipersonal (PAICMA) reporta 10.189 víctimas de minas antipersonal entre 1982 y 2012 (2013, pp. 32-33).

En Colombia, han aparecido los personajes de la guerra y la exclusión indefinida que hasta ahora eran invisibles: los sobrevivientes. Naturalmente, los sobrevivientes han existido desde siempre, pero ahora son visibles en la esfera pública. Y su presencia alude inmediata e inevitablemente a la fuerza, la exclusión, el abandono, la 
injusticia, la indiferencia, cuyas causas han dependido de un largo proceso histórico de violencia, inequidad y abandono estatal. Pero la nuda vida de los cientos de desterrados, refugiados, desaparecidos no implica examinar, únicamente, la noción de orden jurídico-político colombiano, el cual ha dependido, históricamente, de la guerra, la muerte, el abandono, sino también, y por supuesto, del tipo de sociedad y sus fragilidades e imposibilidades, así como sus acciones ético-políticas respecto a las preguntas y los desafíos de este nuevo actor político. Porque los sobrevivientes son algo más que una especie de seres humanos dispuestos para la muerte mediante el olvido, la indiferencia, la exclusión, puesto que su figura representa públicamente la excepción permanente en la que han vivido durante generaciones enteras. Los sobrevivientes colombianos constituyen una masa extraordinaria de hombres y mujeres reducidos a la mera sobrevida, cuyas narrativas permiten comprender lo ocurrido en toda su dimensión y, adicionalmente, otorgan nuevos para pensar el derecho y la política. Y, sin embargo, esta masa informe, incalculable y móvil de la barbarie es ignorada e, incluso, despreciadas por la mayoría. La respuesta a la crisis del derecho moderno, debido a su inminente y compleja relación con la violencia sacrificial de los individuos, implica pensar otros sentidos de lo jurídico que dependan, estrictamente, del reconocimiento de aquella alteridad que padece o ha padecido históricamente los efectos de la violencia sacrificial.

Bajo esta perspectiva, es preciso reconocer la voz del sobreviviente al momento de construir otras nociones de derecho, con miras a entender su histórica relación con la violencia guerrera y, por consiguiente, con los homicidios, las torturas y las desapariciones, pero, también, con las apropiaciones de los territorios, la extracción de los recursos, la legalización de las usurpaciones, entre otros. La autoridad de quienes narran sus perspectivas acerca del conflicto armado y, a su vez, del conflicto social, económico, político deviene, justamente, de la experiencia del horror en el país. Y esa experiencia desconocida o ignorada por la mayoría, ya que la consideran como algo normal, habitual o natural respecto a ciertos individuos y espacios de la geografía nacional, permite examinar, más claramente, las modalidades de la violencia impetradas por los distintos guerreros, así como sus efectos en la vida de algunos y, por supuesto, en las dinámicas del cuerpo social. En definitiva, la escucha atenta a la voz del sobreviviente advierte que la violencia no es, en modo alguno, algo meramente natural e inevitable, una suerte de destino trágico sobre quienes la padecen, o lo que es lo mismo, sobre los más débiles de la comunidad, sino, en cambio, el resultado histórico de las variadas relaciones de poder y de sometimiento de algunas clases, grupos y particulares dominantes sobre los demás, las cuales han sido sancionadas y protegidas por el derecho. Empero, los pliegues del poder y sus formas de enmascaramiento y conservación violenta, también envuelven los distintos daños e injusticias que se han producido generacionalmente sobre los vencidos.

Porque la muerte no procede, solamente, de la acción de matar y de morir, ya que alude a procesos más complejos en virtud de los cuales la vida humana ha sido puesta en bando, es decir, abandonada a un proceso de degradación continua, o lo 
que es lo mismo, de progresiva destrucción. Los daños provenientes de la muerte, la tortura, la mutilación son, por supuesto, más visibles, tangibles y reconocibles en relación con otras afectaciones sobre la vida humana, las cuales, por ser más opacas, difusas e indeterminadas temporalmente, se tornan incluso más letales en sus formas y proporciones numéricas. En este sentido, la interminable degradación del sobreviviente implica la prolongación histórica de su nuda vida, la cual puede ser apropiada y eliminada por cualquiera en cualquier instante. Los sobrevivientes deben, pues, convertirse en la piedra angular de la esfera pública por venir, y no solo en meros ornamentos de justificación de la maquinaria estatal.

\section{ENEMISTAD ABSOLUTA}

Lo político se ha definido históricamente mediante la dialéctica entre patricios y plebeyos, siervos y señores, amos y esclavos, burgueses y proletarios, y, finalmente, entre amigos y enemigos. Estas oposiciones implican siempre la unidad en el sentido de la identidad: La guerra se ha entendido como la expresión extrema de la enemistad, los pueblos luchan por el sometimiento y la anulación de otros pueblos ónticamente diferentes y por la conservación de sus propias formas de existencia. Sin embargo, cuando la guerra es una lucha armada que no se libra en el afuera, en la exterioridad, sino en el adentro, en la interioridad de una comunidad civil, la cuestión resulta altamente problemática, ya que se exige la identidad ontológica e ideológica de las distintas unidades políticas. El Estado se entiende como una unidad que agrupa a los individuos que se encuentran unidos por un vínculo de afectividad, identidad, raza, lengua, territorio, e ideología, lo cual les permite distinguirse de otras comunidades. De modo tal, que los ciudadanos están obligados a defender con sus vidas las leyes y el territorio que configura la comunidad política. Por su parte, las organizaciones revolucionarias respecto al Estado se encuentran agrupadas bajo la modalidad de partido y en asocio con otros grupos o asociaciones que apoyan la insurrección. Desde el punto de vista organizacional, los combatientes activos no luchan como sujetos individuales, partidarios de sí mismos, sino como militantes de un mismo e idéntico partido - partisan-. El hombre que lucha en su propio nombre y representación no es en sentido estricto un revolucionario, ya que combate como partidario de sí mismo. El revolucionario combate, pues, en un frente político y es precisamente su carácter político lo que posibilita distinguirlo de otras agrupaciones armadas apolíticas. El partido revolucionario representa, en cambio, una totalidad de partidarios que militan juntos bajo una misma ideología. Este estar y hacer juntos la guerra es lo que les permite agruparse bajo estructuras de mando y reglamentación que regulan el combate contra el enemigo.

En Colombia, la guerra y la democracia han coexistido como dos realidades históricamente complementarias. Esto resulta verdaderamente paradójico si se admite que el régimen democrático niega la lucha armada interna como una forma de tramitar los antagonismos. Los actores armados, -bien sea de derecha, que reclaman 
el restablecimiento de un régimen fuerte para devolver al Estado su capacidad de actuar; bien sea de izquierda, que acusan a las clases privilegiadas de promover la injusticia y la desigualdad social, y que solo una revolución puede poner fin a las condiciones de inequidad existentes- se oponen a las reglas y procedimientos democráticos mediante el ejercicio de la guerra. La democracia contiene, en cambio, distintas prácticas e instituciones no violentas para gestionar los múltiples y, en ocasiones, contradictorios intereses de los individuos que integran la comunidad política, bien sea a través de los mecanismos partidistas y electorales, bien sea a partir de un proceso deliberativo neutral, libre y público entre individuos. Estos mecanismos no implican, en todo caso, la desaparición definitiva de las oposiciones inherentes a las relaciones sociales, las cuales fluyen en términos de afinidades y contradicciones. Considerar lo contrario, esto es, que la democracia conduce a la paz permanente entre los Estados y entre estos y sus ciudadanos constituiría no solamente la pura y radical despolitización de la democracia, sino también de la diversidad de los sujetos democráticos (Ruiz \& Mesa, 2013, p. 41). El reconocimiento del pluralismo implica, al mismo tiempo y, por las mismas razones lógicas, la aceptación del antagonismo permanente. De manera que el orden jurídico-político democrático no existiría sin el conflicto y sin el reconocimiento de la figura del opositor $-\mathrm{o}$ en términos de Chantel Mouffe, del adversario-. En la democracia pluralista, cuyas dimensiones constitutivas son el poder y el conflicto, la dialéctica entre amigos y enemigos desaparece y, en su lugar, hace aparición la figura del adversario como una condición sine qua non de la vida comunitaria.

Desde esta perspectiva, la política niega el binomio ellos/nosotros y, por consiguiente, reconoce un régimen en que los opositores dejan de ser una amenaza, un enemigo radical a quien destruir o eliminar y, en cambio, se constituyen en adversarios, quienes puedan defender sus ideas políticas al igual que el nosotros. En palabras más claras, la definición de lo político entendida como el antagonismo radical de dos agrupaciones enemigas, cede ante una relación de agonismo propia de una relación entre adversarios: "El antagonismo es una lucha entre enemigos, mientras que el agonismo es una lucha entre adversarios" (Mouffe, 2003, p. 114). Sin embargo, en los estados de guerra reales o potencial desaparece la lucha entre adversarios políticos y, en su lugar, emerge la lucha entre enemigos políticos: la lucha del adversario se convierte, pues, en la lucha del enemigo político. La oposición común entre los adversarios se desplaza, entonces, hacia el antagonismo radical de la guerra, cuyo propósito reside en aniquilar o pactar con el enemigo. Y el enemigo constituye ahora, al igual que el adversario, una condición de existencia y posibilidad del orden, ya que sin el reconocimiento del enemigo político no habría ninguna probabilidad de paz.

En Colombia es bien sabido que la situación de guerra o anormalidad permanente ha impedido consolidar una política del adversario y, en cambio, ha servido para instaurar una política de la enemistad absoluta. En el país, se ha declarado una forma de organización política democrática y, al mismo tiempo, se ha admitido la existencia 
de una confrontación armada de larga duración, en la cual se han enfrentado históricamente distintas fuerzas, tanto estatales como revolucionarias, paraestatales o meramente delincuenciales. El estado de guerra ha incidido directamente en las dinámicas políticas y sociales, bien porque los actores armados ilegales han injerido en numerosas esferas institucionales -incluyendo el poder público y los organismos de control-, bien porque el conflicto ha afectado la totalidad de las formas de vida social. De este modo, el reconocimiento de un enemigo político identificable, fiable y familiar ha desaparecido paulatinamente en la brumosa y siempre indiscernible multitud de enemigos potenciales, siempre sustituibles y, simultáneamente, en las inauditas e innumerables violencias. Este hecho se presenta en términos de una fatalidad absoluta, especialmente, sobre aquellos que padecen la violencia guerrera. $\mathrm{Y}$ en Colombia, este padecimiento, que se acrecienta a lo largo del conflicto armado, ha asumido los rasgos de una violencia sin precedentes. En efecto, la indeterminación en la manera de nombrar, caracterizar y significar el conflicto armado colombiano ha incidido directamente en la forma de nombrar el enemigo y, por supuesto, de combatirlo o disuadirlo. De suerte que el reconocimiento y, a su vez, el desconocimiento y la aniquilación del enemigo han constituido un movimiento pendular en virtud de los distintos períodos históricos y movimientos políticos, sociales, económicos. El tratamiento del enemigo en la guerra colombiana también ha dependido de las distintas formas de denominación y, por lo tanto, de negación: insurgente, enemigo político, enemigo absoluto, aliado, facineroso, bandido, terrorista. Porque el desconocimiento del enemigo político, ocasiona su desaparición del ámbito político $\mathrm{y}$, con él, por supuesto, de las posibilidades de establecer un conjunto de reglas y procedimientos, a fin de limitar la violencia y elaborar los tratados o acuerdos de paz que permitan transitar hacia la democracia.

Negar al enemigo político por considerarlo una figura contradictoria respecto a la democracia ocasiona, justamente, su destrucción más radical. Lo contrario, esto es, la admisión de la disimetría de fuerzas e ideologías implica reconocer las posibilidades de una coexistencia siempre negociada. En el ámbito colombiano, la negación de la enemistad política ha implicado una prolongación de la disimetría original entre los combatientes, lo cual no les ha dejado otra salida que la muerte o el sometimiento. Esta circunstancia ha sido, sin embargo, extraordinariamente compleja, ya que cada autoridad ha asumido un conjunto de discursos y de prácticas distintas respecto al conflicto y la condición del enemigo. Durante los últimos mandatos, por ejemplo, el gobierno de Andrés Pastrana Arango (1998-2002) reconoció formalmente la existencia del conflicto político armado y, por lo tanto, de las Fuerzas Armadas Revolucionarias (FARC-EP) como un movimiento rebelde con pretensiones de transformar políticamente al Estado: "He reconocido el carácter político de su organización”. En efecto, el 07 de enero de 1999 se instaló la mesa de diálogo entre el Gobierno Nacional y las Fuerzas Armadas Revolucionarias - FARC-EP. Las palabras de Pastrana, inaugurales, públicas y en voz alta fueron las siguientes: 
Hoy venimos a cumplir una cita con la historia. Sabemos que los ojos de todos, de cada trabajador, de cada empresario, de cada campesino, de cada madre de familia, de cada desplazado, de cada soldado, de cada insurgente, están pendientes de nosotros. Hemos venido a encontrarnos con un ayer de contrastes, de luces y de sombras, de logros y de fracasos, de sucesos que nos llenan de orgullo y de otros que nos abruman. Pero también a construir un destino común que tenga el rostro y la dimensión de nuestros sueños, de nuestros sacrificios y de nuestra generosidad.

Estas palabras, que establecen las primeras enunciaciones performativas sobre el proceso de paz, no se dirigen a cualquier destinatario, son destinadas a un "nosotros" que omitiendo al "ellos" invocan a los amigos y conjura a los aliados en el acto de instalación. La autoridad compromete aquí la memoria en el presente invocando a los ausentes: Secuestrados, desparecidos, muertos sacrificados en la histórica confrontación armada. La ausencia de ellos se hace presencia en el acto de la instalación: nombrarlos ahora implica la obligación social de velar por ellos. Y seguidamente, Pastrana afirma:

Queridos amigos: El dolor de las familias, el padecimiento de los secuestrados y la incertidumbre provocada por los desaparecidos pesan mucho en nuestros corazones. Por todos ellos y, sobre todo, por la memoria de las víctimas que ha dejado esta tragedia nacional, los invito a un momento de reflexión en homenaje respetuoso [...] Es claro que los esfuerzos por la reconciliación deben conducir a que cesen la muerte y el secuestro.

En palabras de Lazzarato (2007, p. 18), las enunciaciones performativas no son, simplemente, la expresión de un punto de vista, de una opinión o de una descripción. Estas enunciaciones actúan sobre los auditorios contribuyendo a restablecer la constitución social de aquéllos a quienes se dirigen: La condición de amigos-colombianos-víctimas, defensores de la paz-extranjeros. Además, estas enunciaciones determinan acciones sociales ligadas que intervienen en situaciones socio-políticas: decretan, establecen, restablecen.

[...] Nada ni nadie nos debe impedir el derecho que tenemos a construir un país en paz. Un país en donde la bandera patria se iza orgullosa [...] Una patria unida con un destino común. Segura de sí misma [...] Colombianos: la hora de la paz ha llegado y nada podrá detenerla [...] Todo el que sueñe la patria tiene derecho y obligación de participar en este esfuerzo que nos debe vincular a todos. Hay gente que está sólo de forma intelectual con la paz pero no quiere hacer sacrificios por ella.

Pastrana insiste aquí en la idea del sacrificio como obligación social ligada al acontecimiento del discurso que incluyen, al mismo tiempo, por destino y definición al autor: El yo como sujeto que enuncia estas palabras se encuentra, anticipadamente, comprendido y determinado en el nosotros. La obligación social derivada de esta enunciación implica el acto de creación de la mesa de negociación: “[ ...] no podemos 
olvidar las víctimas de este conflicto. No quiero repetir la amarga experiencia que como yo- han vivido y viven tantos colombianos. Nuestro sacrificio no puede pasar inadvertido". Y de manera inmediata agregó:

Estamos dispuestos a discutir, a disentir, a proponer, a evaluar pero, sobre todo, a construir. Esa es la esencia misma de una democracia [...] como presidente de todos los colombianos quiero una nación próspera y optimista. Sin violencia, comprometida contra la corrupción, progresando contra la pobreza y con sus mejores esfuerzos dedicados al bienestar de mis compatriotas. En esta tarea de cambio se encuentra empeñado mi gobierno. He liderado ese proceso con seguridad y dirección" "[...] como jefe de Estado, estoy aquí expresando la voz de un país que quiere paz, que reclama paz, que busca justicia social y está dispuesto a darle curso a la política como ejercicio del bien común. Un país que reclama libertad con seguridad y pide se le garantice libertad con dignidad. El enunciado referente a la democracia funda el lazo social, la comunidad, la igualdad, la unidad nacional, la amistad de todos los colombianos. Es un lazo del que deriva el acto social, la obligación o compromiso realizativo: la promesa de la paz con justicia social y unidad nacional.

El enunciado referente a la democracia funda el lazo social, la comunidad, la igualdad, la unidad nacional, la amistad de todos los colombianos, incluyendo a la insurgencia. Es un lazo del que deriva el acto social, la obligación o compromiso realizativo: La promesa de la paz con justicia social y unidad nacional. Luego de una serie de objeciones, críticas y tensiones en el proceso de negociación, Pastrana pronunció la ruptura de los diálogos de paz con las FARC-EP, el 20 de febrero del 2002:

[...] A nivel interno, hemos logrado que todo el país, todos y cada uno de los colombianos, se comprometa con la paz. Antes se pensaba que ese era un problema únicamente del Gobierno con la guerrilla. Hoy somos conscientes de que es una guerra que nos han declarado los violentos a la sociedad y que somos todos los que tenemos que trabajar para detenerla. Hoy la paz es el tema central del país. Desde el punto de vista político, le hemos propinado la más grande derrota de toda su historia a las FARC y logramos que la guerrilla perdiera el poco apoyo que había logrado reunir en sus más de 30 años de existencia. Hoy nadie en Colombia cree que la guerrilla sea una opción política y su respaldo popular es prácticamente cero. Ya nadie cree que están a favor del pueblo: jestán en contra del pueblo! Y hemos hecho algo más, dentro de nuestra política de paz: Mientras las FARC exigían a través de la violencia mejoras sociales para los colombianos, pero no hacían más que generar miseria, desempleo y dolor a su alrededor, mi Gobierno puso en marcha, con el Plan Colombia, la estrategia de inversión social más grande de nuestros tiempos. Esa revolución que la guerrilla pretende promover, nosotros ya la estamos haciendo. ¡Porque la revolución social se hace con obras, no con terrorismo! Miremos unos datos que hablan por sí solos: Mi Gobierno dejará invertidos más de un billón de pesos, 
representados en nuevos empleos, viviendas, carreteras y educación, en programas sociales que beneficiarán a más de 2 millones de los colombianos más necesitados. ¡Eso sí es una revolución social! Así que no hemos perdido en estos difíciles años. Al cabo de todo, si hacemos un balance objetivo, hoy estamos más preparados que nunca, más unidos que nunca, respetados y apoyados internacionalmente y más fuertes militarmente para enfrentar la violencia que nos agobia.

El reconocimiento o, en su lugar, el desconocimiento de los opositores armados por parte de la autoridad, no solo constituyen las circunstancias esenciales en la constitución del enemigo, sino también, y más exactamente, en su tratamiento político: Mientras la definición de los opositores como enemigos políticos hace posible su inclusión en la ceremonia de paz, la negación de los enemigos y su puesta en bando como enemigos absolutos o radicales los sitúa en el plano de la exclusión y, por lo tanto, cualquiera puede matarlos sin cometer homicidio. La nuda vida del enemigo absoluto está expuesta a la muerte legítima. En palabras más claras, el enemigo político pasa a convertirse en enemigo absoluto del Estado y la sociedad, razón por la cual cualquiera puede eliminarlo sin consecuencias jurídicas. En la misma alocución, Pastrana afirma:

¡No podemos soportar más sevicia y crueldad de parte de quienes dicen querer la paz! ¡No es posible firmar acuerdos, por un lado, y poner el fusil en la cabeza de los inocentes, por el otro! Colombia entera dice: ¡NO MÁS! ¡Nos cansamos de la hipocresía de la guerrilla. La guerrilla -en su terquedad y su sordera- ha cometido demasiados errores graves en todos estos años, en contra de la posibilidad de la paz. Ellos mismos -no nadie más- se han cerrado la puerta para el diálogo. Ellos mismos han logrado que ya nadie crea en su voluntad de paz ni en su palabra. Ellos mismos se han negado un espacio político en el país. Después de los terribles sucesos del 11 de septiembre del año pasado yo se lo dije a la guerrilla en varias ocasiones, incluso desde el mismo foro de las Naciones Unidas: "A ellos les correspondía definirse con sus actos: $\mathrm{O}$ son un grupo de insurgencia política o son una organización terrorista". O se respeta la vida y dignidad del ser humano, o no se las respeta, como es el caso de las infracciones al Derecho Internacional Humanitario. "Tristemente, hoy son ellas las que han firmado su propia definición y ya nadie puede dudar de que, entre política y terrorismo, las FARC optaron por el terrorismo". Recuperado de: http:// www.eltiempo.com/archivo/documento/MAM-1308284

Empero, los efectos de la ruptura avanzan en la puesta en bando ya no solo de los enemigos, ahora convertidos en terroristas, sino de toda la sociedad sobreexpuesta en adelante a la guerra y al sacrificio de sus vidas, cuerpos y posesiones. Porque la autoridad en Colombia no ha decidido, únicamente, sobre la guerra y el carácter del enemigo en aras de pacificar la comunidad, sino también, y más precisamente, sobre 
la vida y la muerte de los ciudadanos cuya vida ha sido continuamente reducida a nuda vida con miras a su sacrificio:

Vienen tiempos difíciles, sin duda, en los que se requerirá la unión de todo el país en torno a sus instituciones democráticas. Nadie puede celebrar la situación a la que nos han llevado las FARC. Pero el país no se va a acabar ni vamos a entrar a una terrible guerra sin cuartel. Eso sí: tenemos que estar preparados, porque es muy posible que se incrementen los actos de terrorismo. Ante esto los colombianos de bien tenemos que estar unidos, hoy más que nunca, y tenemos que estar listos a colaborar con las autoridades y a denunciar cualquier conducta sospechosa. ;La unión hace la fuerza! Olvidemos las divisiones internas y los conflictos pequeños y cerremos filas contra la violencia. No vamos a dejar, de ninguna manera, que el terrorismo nos divida. Todo lo contrario: ¡Vamos a demostrar valor civil, a rechazar a los violentos y a defender a nuestro país! Así lo estamos haciendo ya todos los colombianos, como ocurrió esta misma noche cuando nos manifestamos todos, de forma pacífica pero contundente, contra la violencia de los intolerantes. Que lo sepan las FARC, que lo sepan todos los grupos que insisten en sembrar violencia y muerte a su alrededor: ¡Un ejército de 40 millones de colombianos es invencible! ¡Nunca podrán derrotarnos! ¡Nunca, ni en sus sueños, podrán obtener el poder por las armas, porque aquí el poder solo se gana en las urnas de la democracia! Yo seguiré buscando la paz, de la mano de todos ustedes. Pero no someteré al pueblo colombiano a la arrogancia de unos interlocutores que dicen querer la paz, pero que disparan contra ella. El libro de la paz sigue abierto y solo se cerrará el día en que la alcancemos. Que Dios los bendiga. Y que Dios me bendiga. Y que San Miguel Arcángel nos proteja. Recuperado de: http:// www.eltiempo.com/archivo/documento/MAM-1308284

Después de la apelación a los cielos en virtud de la ruptura de los diálogos del Caguán, y al finalizar el gobierno de Pastrana, Álvaro Uribe Vélez obtuvo una amplia votación gracias a su campaña política de derrotar militarmente a los grupos violentos. A diferencia de su antecesor, Uribe negó permanentemente la existencia del conflicto con las FARC-EP y, en consecuencia, definió a la insurgencia como una agrupación de terroristas contra el pueblo. Este propósito es refrendado por

1 En las últimas décadas se han desarrollado en el país múltiples procesos de diálogo y de negociación entre los gobiernos nacionales y los grupos alzados en armas. Algunos culminaron con la desmovilización y la incorporación de los ex-combatientes a la vida política, tal como aconteció con el gobierno de Belisario Betancur Cuartas (1982-1986) y un amplio sector de las guerrillas de las FARC, EPL, M-19, PRT y la facción armada del movimiento indígena Quintín Lame. Otros procesos terminaron con la ruptura, tal como aconteció en el período de Pastrana, cuyos efectos más precisos respecto a la insurgencia consisten en el giro semántico y pragmático del discurso estatal relativo a la supresión del carácter de político del enemigo y su definición como terroristas. De esta manera, durante el período de Uribe, se suprimió el espacio político de la negociación, por lo menos con las FARC, intensificándose, en su lugar, el tratamiento militar y los dispositivos sacrificiales: derramamiento de sangre, crueldad, destierro, tortura, entre otros. 
Uribe, quien destacó en su discurso "No debe haber cartas ocultas" pronunciado en la graduación de subteniente de la Policía Nacional, el 5 de junio de 2005:

[...] a diferencia del pasado, esta Ley no se preocupa solamente por la reconciliación, se preocupa - por primera vez, una ley de paz en Colombiapor la justicia y por la reparación a las víctimas. En el pasado sólo importaba desmovilizar a los terroristas y se hacía a un lado el interés por la justicia y se hacía a un lado el interés por la reparación de las víctimas. Esta ley es clara que no puede haber amnistía ni indulto para aquellos que hayan cometido delitos atroces, sean guerrilleros o paramilitares. Esta ley se debe aplicar por igual a guerrilleros o a paramilitares. No es bueno que algunos sectores de opinión, que algunos líderes de opinión sigan acariciando la esperanza de que a los unos hay que pasarlos por la guillotina y a los otros hay que darles perdón total, contraviniendo la Constitución y las leyes.

Y, seguidamente agrega: “[...] el sufrimiento de los colombianos es igual cuando el delito lo comete el guerrillero, que cuando el delito lo comete el paramilitar". Bajo esta consideración, Uribe se refiere simultáneamente a los grupos al margen de la ley, así como a los gobiernos anteriores y, por supuesto, a su propio gobierno:

¿Qué pasó con él antaño? Que se le diga al país claramente, si las instituciones, si los gobiernos tuvieron o no complicidad con él en el pasado, para perseguir otro grupo narcotraficante. Y hago esa pregunta con una autoridad moral. ¡Este Gobierno, yo como Presidente de Colombia, nos hemos propuesto - con la Fuerza Pública - derrotar a los terroristas, sin aliarnos con otros terroristas! (Uribe, Graduación de subtenientes de la Policía Nacional, Bogotá, Cundinamarca, 2005).

Según Uribe, la acción de su gobierno se encaminó a derrotar a los narcotraficantes y terroristas -refiriéndose a la guerrilla, sin nombrarla- y prescindiendo de cualquier alianza con otros grupos terroristas -entiéndase paramilitares-. Según él, este tratamiento militar equivalente respecto a los grupos de terroristas y de narcotraficantes otorga a su personalidad toda la autoridad moral para dirigirse abiertamente y sin clandestinidades a sus compatriotas. Porque:

¡La paz no nace de la complicidad de las instituciones con los terroristas! ¡La paz no nace de consentir terroristas! ¡La paz nace del ejercicio firme de la autoridad! ¡Nosotros creemos que la paz nace del ejercicio firme de la autoridad! Un ejercicio de autoridad, para el cual no requiere de ninguna alianza. De acuerdo con mis adversarios, bien podría haber hecho yo una alianza clandestina con el paramilitarismo para derrotar a la guerrilla. ¡Yo no nací para esas clandestinidades! ¡Yo soy combatiente, lleno de defectos como toda obra humana, pero combato de frente! La instrucción que se le ha dado a las instituciones de Colombia es derrotar por igual a guerrilleros y a paramilitares. iSi no, que vengan las cifras! (Uribe, Graduación de subtenientes de la Policía Nacional, Bogotá, Cundinamarca, 2005). 
En efecto, Uribe respalda su afirmación a partir de acciones de poder concretas:

Cuando aquí no se perseguía al paramilitarismo, cuando nos entregaron a nosotros una fuerza crecidísima de paramilitares, en este Gobierno casi 10 mil paramilitares han sido puestos presos y hasta hace poco, iban dados de baja más de 1182 paramilitares. Cuando este Gobierno empezó, Colombia tenía casi 30 mil homicidios por año, este año van 6.686 con cinco meses causados del año. Se nota una enorme tendencia de disminución, quisiéramos poderle decir a la Patria que aquí no hay asesinatos, pero de todas maneras se ve una gran tasa de descenso. Cuando este Gobierno inició, en la Patria asesinaban a 66 conciudadanos por cada 100 mil habitantes. Este año van 15 por cada 100 mil habitantes. Confiamos que se consolide y se profundice más esta tasa de descenso. Colombia tuvo años en los cuales asesinaban 168 integrantes de las organizaciones sindicales de trabajadores. Este año van 3. Quisiéramos rápidamente decir que no han asesinado uno solo. Este año, también va una gran reducción en el asesinato de periodistas y en el asesinato de maestros. Nos preocupa lo que ha ocurrido recientemente con los Concejales de Puerto Rico en el departamento de Caquetá. Allí, como en muchas partes de Colombia tenemos que hacer esfuerzos superiores. Cuando este Gobierno empezó casi 400 alcaldes de la Patria, elegidos popularmente, no podían ejercer sus funciones, estaban por allí escondidos y arrinconados por las amenazas de los terroristas. Hoy, salvo uno o dos casos, todos ejercen libremente sus tareas bajo la protección de la Fuerza Pública". Pero General Castro (Jorge Daniel, director de la Policía Nacional), apreciados oficiales, mis compatriotas, todos de la Policía: vamos a aumentar nuestros esfuerzos para proteger más eficazmente a los Concejales. Cuando este Gobierno inició en la Patria secuestraban 3050 personas al año. Este año van 280 secuestros, casi la mitad del año. Solamente en relación con el año pasado, hemos tenido una disminución del 61,1 por ciento. Cada domingo hay elecciones en los municipios, esos candidatos tienen hoy las garantías que no tenían, una Fuerza Pública que ha posibilitado que las ideas en Colombia se expresen libremente, una Fuerza Pública que ha seguido al pie de la letra la instrucción que me he permitido dar como Presidente, de que se proteja por igual al político más comprometido con las tesis de gobierno y al político más resuelto a adelantar tareas de oposición. ¡Eso enaltece la democracia!". Recuperado de: http://historico.presidencia.gov. co/discursos/discursos2005/junio/cartas_ocultas.htm

En palabras de Uribe, estas acciones que enaltecen la democracia constituyen los presupuestos del proyecto de Seguridad democrática. Y: "Todo esto se debe a su esfuerzo, a la heroicidad de las Fuerzas Armadas de Colombia, de todas ellas, de su Policía" (Uribe, Graduación de subtenientes de la Policía Nacional, Bogotá, Cundinamarca, 2005). Las Fuerzas Armadas y la Policía cobran un papel esencial 
en el Gobierno del Presidente Uribe, así como las SS tenían un rol fundamental en el régimen nazi: Vigilar, custodiar, control, ejecutar, castigar, proteger el régimen. Según Uribe, en el aumento del brazo armado del Estado, se funda, precisamente, la esperanza del Estado de seguridad, o lo que es lo mismo, en el sacrificio de cientos de soldados y de víctimas: "[...] Aumenta nuestra esperanza de que vamos a tener, más temprano que tarde, una Patria sin narcotráfico, una Patria sin guerrilleros terroristas, una Patria sin paramilitares terroristas" (Uribe, Graduación de subtenientes de la Policía Nacional, Bogotá, Cundinamarca, 2005). Pero, además del incremento de la violencia estatal en virtud del número creciente de policías y soldados, así como de fuerzas especiales existen, según Uribe, otras instituciones resueltas a derrotar al narcotráfico y al terrorismo: “¡Hay un Presidente, unos ministros, unos altos mandos, un Fiscal, una administración de justicia, todos resueltos a derrotar el terrorismo!" (Uribe, Graduación de subtenientes de la Policía Nacional, Bogotá, Cundinamarca, 2005). En palabras más claras, la autoridad constituye una unidad nacional dispuesta a combatir y derrotar a los grupos de narcotraficantes y terroristas, ya sea como combatientes, ya sea como funcionarios, ya sea como ciudadanos delatores. La movilización total hacia la guerra conforma aquí un sacrificio colectivo en nombre del Estado y el derecho. Según Uribe, a diferencia de gobiernos anteriores en la vida nacional los suyos "tienen que ser procesos de paz seriamente practicados como procesos de paz y no simplemente procesos de fortalecimiento de criminales" (Uribe, Graduación de subtenientes de la Policía Nacional, Bogotá, Cundinamarca, 2005).

Y de inmediato el exmandatario señalaba que la ley de justicia y paz propuesta, a diferencia del pasado, "sólo importaba desmovilizar a los terroristas y se hacía a un lado el interés por la justicia y se hacía a un lado el interés por la reparación de las víctimas" (Uribe, Graduación de subtenientes de la Policía Nacional, Bogotá, Cundinamarca, 2005). Así como Dios, Uribe se arrogó, entonces, la mediación entre las víctimas y los victimarios, pues se concibió como la única institución capaz de encarnarse como tercero capaz de hacer verdad, justicia y reparación. De este modo, el expresidente distinguió a cada instante a los buenos y los malos, las víctimas y los victimarios, lo que, en un conflicto de larga e intensa duración como el colombiano, resulta confuso dado el espacio de porosidad entre las identidades y los roles que se cruzan en una zona de tonalidades tan inciertas. Aun así, dividió a los colombianos en leales y traidores, amigos y enemigos, ciudadanos y terroristas. Esta puesta en bando generó importantes consecuencias en la confrontación bélica y la pacificación negociada del país, ya que se eliminó toda posibilidad de negociación con las FARC $\mathrm{y}$, sin embargo, se acordaron importantes prerrogativas transicionales con los paramilitares articulados en las autodenominadas Autodefensas Unidas de Colombia $(\mathrm{AUC})^{2}$. Durante sus dos períodos presidenciales, Uribe negó el carácter político de

2 En Colombia, la expresión justicia transicional llegó a ser conocida a partir del debate de la Ley 975 de 2005 "Ley de Justicia y Paz", que sirvió de marco normativo para las negociaciones entre el expresidente Álvaro Uribe Vélez y las cúpulas y mandos medios de las Autodefensas Unidas de Colombia (AUC); y que además pretendió la desmovilización de algunos de los miembros de las 
la insurgencia y, en su lugar, reforzó la noción y el tratamiento de enemigo absoluto respecto a la guerrilla de las FARC-EP, a partir del binomio enemigo-terrorista. La estrategia estatal consistió, pues, en distinguir a los guerrilleros combatientes o activos en los distintos frentes y procedimientos militares, quienes fueron catalogados como terroristas que "que hay que acabar: [...] a esos bandidos, todos, y a esas bandas terroristas del narcotráfico, a todos, a todos tenemos que acabarlos para que el país pueda vivir en paz" (Semana, 2010, párr. 5), mientras que los guerrilleros delatores, fueron estimulados con el pago de recompensas por información y, aún más, por el asesinato de sus compañeros de lucha.

Por su parte, los reinsertados, que dejaron las armas e informaron a las fuerzas armadas sobre la localización, el número y las estrategias de la insurgencia en su oposición militar al Estado, obtuvieron el estatus de delincuentes a quienes se les podía aplicar las leyes. La autoridad decidió, entonces, sobre la categoría del enemigo y su tratamiento jurídico-militar. No obstante, en su trabajo El Lenguaje del presidente Uribe frente al terrorismo, Eduardo Posada Carbó advierte el incremento progresivo de la violencia por parte de Uribe, ya que sus referencias respecto a la insurgencia pasaron de las denominaciones "grupos irregulares", "actores irregulares armados", "grupos violentos" a la etiqueta "grupos terroristas". En la Asamblea Iberoamericana de Ministerios Públicos celebrada el 22 de noviembre de 2002, Uribe indicaba: "Aquí no hay un conflicto político [...] aquí lo que hay es terrorismo contra el pueblo" (Carbó, 2009). Durante los períodos del expresidente Uribe, se intensificó la violencia de la máquina estatal y sus dispositivos sacrificiales de forma inusitada: El enemigo era amenazado o eliminado mediante la supresión de su vida, por cuanto desconocía la voluntad de la autoridad. La puesta en bando del terrorista, bandido, criminal, delincuente respecto al orden estatal era objeto de eliminación por cualquiera que

organizaciones guerrilleras (Orozco, 2009, p. 4). Esta disposición normativa contempla, de un lado, las medidas tomadas por el gobierno de Uribe para llevar a cabo el desarme, la desmovilización y reinserción de los grupos paramilitares e insurgentes y, de otro lado, la satisfacción de los derechos de verdad, y reparación a las víctimas. Durante el debate de la ley, el modelo de justicia transicional (que privilegia el castigo a los victimarios), se impuso al de la justicia restaurativa (que acentúa el énfasis en la reparación a las víctimas). No obstante, las exigencias internacionales de castigar ejemplarmente a los perpetradores de graves crímenes de guerra, la autoridad soberana negoció la punición con las AUC, ora por éstos contaban con una fuerza militar, política y económica considerable, y, además, ora por los vínculos del aparato estatal con los paramilitares. Así las cosas, la transición se convirtió en una transacción basada en condiciones altamente beneficiosas, ya que se aplicó la alternatividad penal para los paramilitares, que consiste en la aplicación de una pena que oscila entre cinco y ocho años por delitos de lesa humanidad. La obtención de la alternatividad penal implicaba por parte del beneficiario una serie de obligaciones, a saber: contribuir a su resocialización a través del trabajo, estudio o enseñanza durante el tiempo que permaneciera privado de la libertad y promover actividades conducentes a la desmovilización del grupo armado al que había pertenecido. Además, los beneficiaros tienen el deber de reparar a las víctimas a través de cinco mecanismos: la entrega al Estado de bienes obtenidos ilícitamente para la reparación de las víctimas; la declaración pública que restablezca la dignidad de la víctima y de las personas más vinculadas con ella; el reconocimiento público de haber causado daños a las víctimas, la declaración pública de arrepentimiento, la solicitud de perdón dirigida a las víctimas y la promesa de no repetir tales conductas punibles; la colaboración eficaz para la localización de personas secuestradas o desaparecidas y la localización de los cadáveres de las víctimas y la búsqueda de los desaparecidos y de los restos de personas muertas (Ruiz \& Londoño, 2010). 
dispusiera de su vida, sin cometer homicidio. Aún más, el homicidio del terrorista era recompensado económicamente por el Estado.

La muerte de Manuel de Jesús Muñoz Ortiz, alias Iván Ríos, y jefe del Bloque Central de las Fuerzas Armadas Revolucionarias, a manos de Pedro Pablo Montoya, alias Rojas, revela, precisamente, la nuda vida de aquel terrorista que puede ser asesinado a favor del Estado. En este sentido, el entonces ministro de Defensa, Juan Manuel Santos emitió un comunicado sobre el homicidio de Ríos y las implicaciones políticas respecto a Rojas (2008):

5. Se decidió reconocerle el pago de una recompensa a las tres fuentes principales, al igual que a alias "Rojas" por la información suministrada. El monto de la recompensa que recibirá cada uno será determinado por el comité y puede llegar a sumar un máximo de 5 mil millones de pesos. Estos pagos al igual que todos los que se han realizado en el programa de recompensas, serán supervisados por los organismos de control.

6. A alias "Rojas" se le reconocerá una importante suma por la información estratégica contenida en el computador que pertenecía a "Ríos" y que fue entregado por "Rojas" a las autoridades, así como por los datos almacenados en memorias USB que están siendo analizadas por parte de las autoridades judiciales.

Empero, el mismo comunicado advierte que la muerte del guerrillero se logró gracias a la cooperación de "[...] diferentes fuentes humanas, en especial de milicianos y desmovilizados cercanos a su entorno, así como de campesinos que fueron desplazados por alias "Iván Ríos"'. De ahí que todos los ciudadanos puedan disponer lícitamente de la mera vida, vida biológica, nuda vida de aquel que ha sido puesto en bando: La autoridad sitúa al homo sacer fuera de ley y, por consiguiente, el soldado o cualquier ciudadano pueden matarlo lícitamente por fuera del combate y de la normativa internacional sobre la guerra.

La muerte de un hombre sin ninguna consecuencia jurídica, fue suscrita por el entonces fiscal de la Nación, Mario Iguarán, quien luego de visitar al guerrillero Rojas en la cárcel, señaló:

En principio, la Fiscalía no haría imputación por homicidio al señor alias 'Rojas' [...] Vamos a valorar no sólo la versión de alias 'Rojas', también las circunstancias en que ocurrieron los hechos, circunstancias tales como que hacía parte de una organización armada donde la vida no vale nada, ni siquiera para los miembros de la misma organización (Iguarán citado por Coronell, 2008).

Este planteamiento indica, entonces, que la nuda vida del enemigo es una vida que no merece ser vivida $y$, por lo tanto, cualquier individuo de la comunidad puede usufructuarla y eliminarla en nombre de la conservación del Estado y el Derecho. En este sentido, Luigi Ferrajoli hace notar las consecuencias de semejante letalidad: 
La etiqueta "terrorismo", como sinónimo de pulsión homicida irracional, sirve para caracterizar al enemigo como no-humano, no-persona, que no merece ser tratado con los instrumentos del derecho ni con los de la política. Es el vehículo de una nueva antropología de la desigualdad, marcada por el carácter tipológicamente criminal, demencial e inhumano, asociado al enemigo, $y$, de este modo, también de una nueva y radical asimetría entre "nosotros" y "ellos". (2007, pp. 11-12).

\section{GUERRA PERMANENTE}

"Las dimensiones de la violencia letal muestran que el conflicto armado colombiano es uno de los más sangrientos de la historia contemporánea de América Latina" (Centro Nacional de Memoria Histórica, 2013, p. 31). En Colombia, la confrontación armada ha obedecido a múltiples causas relacionadas con el bipartidismo, la exclusión y la inequidad histórica respecto a ciertos grupos humanos, la apropiación de la tierra, entre otras, lo que ha producido miles de muertos y sobrevivientes. El conflicto ha sido, pues, multicausal $\mathrm{y}$, al mismo tiempo, extraordinariamente complejo y heterogéneo en relación con sus actores, territorios y modalidades de violencia (Centro Nacional de Memoria Histórica, 2013, p. 31; Hernández, 2003). La historia de la violencia en Colombia consta de distintos períodos, a saber:

1. La Violencia (1948 a 1958). La muerte del líder liberal Jorge Eliécer Gaitán (1903-1948) abre la modernidad en Colombia y, a su vez, el conflicto armado permanente (Hernández, 2003, p. 67; González, 2014, p. 288). En palabras de Ernesto Hernández, este período se caracteriza por "la emergencia de la dictadura civil y militar que reorganiza institucionalmente la república, promueve la industrialización, traza las fronteras agrarias y redistribuye las fuentes de recursos mineros, energéticos y naturales" (2003, p. 67). Asimismo, aparecen numerosas facciones de guerreros y héroes locales que constituyen la larga lista de organizaciones de saqueadores y asesinos: Desquite, Sangrenegra, Tarzán, etcétera. Y otras tantas agrupaciones legales e ilegales se enfrentan en una guerra de aniquilación: El ejército precario y conformado por cooptación -servicio militar obligatorio- se opone a la resistencia campesina agrupada en guerrillas agrarias fuertemente territoriales: Guadalupe Salcedo, Juan de la Cruz Varela, "Charronegro", "Tirofijo". Además de los guerreros, aparecen grandes flujos de personas campesinas desplazados que emigran a las ciudades, configurando grandes redes de marginalidad urbana (Hernández, 2003, p. 67). Paralelamente, el gobierno militar del general Gustavo Rojas Pinilla (19531957) logró reducir y amnistiar gran parte las guerrillas campesinas que, no obstante, se retiran silenciosamente o se disuelven sin deponer las armas frente a la política de desarme y desmovilización. En este punto, Hernández señala que las guerrillas más fuertes entran en procesos de negociación dispersos, lo cual fragmenta y disminuye su fuerza negociadora, acrecienta su aislamiento y 
facilita la traición de los acuerdos por parte de terratenientes, jefes locales y el Gobierno.

En este momento de dispersión, sin embargo, un encuentro con el movimiento socialista y comunista rehabilita las fuerzas insurgentes, dotándoles de nuevos enunciados programáticos que, sin desatender las defensas territoriales, constituyen un "programa de demandas democráticas y un programa político-militar para la toma del poder" (Hernández, 2003, p. 67; González, 2014, p. 302). La guerrilla campesina se reorganiza, entonces, militar y políticamente: Ya no se trata ahora de proteger la tierra, sino de obtener una reforma agraria: "La tierra para el que la trabaja", ante la cual el Gobierno impulsa el hostigamiento (Hernández, 2003, pp. 67-68). Ahora, la pacificación estatal tiene por objetivo las guerrillas reorganizadas en el Sumapaz, $\mathrm{y}$, después de dos años de guerra -los operativos del ejército superan las semanas programadas, por el despliegue de fuerza militar y la brutalidad de las acciones- los grupos guerrilleros se repliegan hacia Marquetalia, donde fundan la organización bajo el nombre de Fuerzas Armadas Revolucionarias de Colombia (FARC). Según un Informe de la Secretaría de Agricultura de la Gobernación de Tolima (1959) citado por el Centro Nacional de Memoria Histórica (2013, p. 113), el período de la violencia produjo importantes consecuencias políticas y económicas:

En primer lugar, estimaron 16.219 muertos entre 1949 y 1957, sin incluir los muertos habidos con fuerzas regulares del Ejército, ni en masacres colectivas, que generalmente eran abandonados a los animales o arrojados a los ríos y precipicios, y tampoco las bajas sufridas por las Fuerzas Armadas. En segundo lugar, cuantificaron que 321.621 personas (es decir, el $42.6 \%$ de la población del Tolima) sufrieron el "exilio" en forma permanentemente o transitoria. En tercer lugar, encontraron que 40.176 propiedades, o sea el $42.82 \%$ del total, pertenecientes a 32.400 propietarios [...], han sido abandonadas transitoria o permanentemente. El 46\% de estas tierras fueron abandonadas entre 1955 y 1956. A su vez, los investigadores advirtieron que la estrategia empleada en la violencia era la misma, tanto si se ejercía con fines políticos como con fines económicos: Actos de terror contra las personas y sus bienes, que concluyen inexorablemente en éxodo colectivo. Logrado este resultado, el paso siguiente es mantener latente el terror, para hacer desistir a las víctimas de presuntos o reales propósitos de reintegrarse a la propiedad abandonada [...]. No es explicable de otra manera el empeño sostenido, y aparentemente ilógico, de destruir casas e instalaciones.

2. Transición de la violencia bipartidista a la subversiva (1958-1982). Según Hernández, la consigna Patria o muerte, venceremos propia de la revolución cubana incentiva la proliferación de fuerzas de izquierda (2003, p. 68; Centro Nacional de Memoria Histórica, 2013, p. 111). Aquí surgen un número importante de guerrillas, las cuales asumen distintos "modelos de revolución armada". En principio, estas agrupaciones se encuentran conformadas por bases sociales 
precarias. Y, posteriormente, algunas se constituyen en organizaciones con cierta influencia en sectores sociales, universitarios, campesinos, sindicales. Hacia mediados de la década de los sesenta, se han conformado y consolidado las guerrillas de corte castrista (Ejército de Liberación Nacional - ELN); la guerrilla de corte comunista pro-soviétio (Fuerzas Armadas Revolucionarias de Colombia - FARC); y la guerrilla maoísta (Ejército Popular de Liberación - EPL). Mientras que el ELN y el EPL estaban conformados por militantes urbanos, estudiantes, obreros y sindicalistas, sacerdotes católicos "revolucionarios" o progresistas inspirados en la teología de la liberación, -tales como Camilo Torres, Domingo Laín, José Antonio Jiménez, Manuel Pérez-, las FARC se constituían esencialmente por campesinos. Asimismo, las dos primeras guerrillas se ubican en el Magdalena Medio, la zona de Chucurí y la del Carare-Opón, Valle del río Sinú, en los límites entre Antioquia y Córdoba. Según González González, en estos casos de asentamiento "se trata de grupos asilados en zonas periféricas, de tendencia a la autodefensa, de estilo partisano y ligados a partidos marxistas-leninistas" (2014, p. 332). Las FARC, en cambio, se ubicaron en zonas de colonización campesina periférica de la región andina. Hernández también alude al nacimiento de las primeras guerrillas urbanas, a saber: Movimiento Autodefensa Obrera (ADO) y el Movimiento de Izquierda Revolucionaria (MIR), las cuales fueron brutalmente aniquiladas (Hernández, 2003, p. 69).

Del mismo modo, otras organizaciones campesinas e indígenas son letalmente reprimidas: Asociación Nacional de Usuarios Campesinos (ANUC) y Comité Regional Indígena del Cauca (CRIC), las cuales promovían la apropiación y la defensa de las tierras. Ante la contención y sometimiento estatal, los miembros de dichas agrupaciones se adhieren a los grupos guerrilleros existentes o se configuran bajo otras formas de lucha, tales como el Quintín Lame (Hernández, 2003, p. 69). Durante esta época se gesta el guerrillero Movimiento de 19 de abril (M-19), el cual copta un número importante de izquierdistas que se quedaron sin partido, y que buscaban, en su lugar, alternativas autóctonas. La respuesta estatal durante este período de confrontación bélica fue la misma: La represión en sus distintas modalidades de violencia. Durante el período de Misael Pastrana Borrero (1970-1974, por ejemplo:

La respuesta a las reivindicaciones del campesinado y de los indígenas se centró -al igual que frente a la agitación de los estudiantes, los maestros y los sindicatos - en la represión política y militar, que corría paralela con la estrategia de terror de los grupos de choque de los terratenientes, y produjo la muerte de numerosos dirigentes campesinos, desplazamiento y abandono forzado de territorios. Las reclamaciones y tomas de tierras fueron asociadas con planes subversivos, y se pretendía establecer nexos orgánicos entre la movilización y la protesta campesina con las guerrillas (Centro Nacional de Memoria Histórica, 2013, p. 131). 
3. Expansión guerrillera, políticas de paz y eclosión paramilitar (1982-1996). Entre finales de los años setenta e inicio de los ochenta, se consolidan los grupos paramilitares, quienes "durante muchos años controlaron regiones muy localizadas -las zonas esmeraldíferas, las tierras de terratenientes y de nuevos dueños de la tierra, los narcotraficantes que empiezan a consolidar sus poderes-“. Según Hernández, durante este período empieza a incorporarse en todas las esferas el prefijo narco, asociado a otro prefijo neo. Esta época se caracteriza por la aparición de una anomalía:

Enclaves industriales en la selva, laboratorios móviles, atomización de la producción de droga, comercio masivo e ilegal de químicos, la hibridación de mercados y sectores productivos, la vigilancia cerrada y continua de ciudades como Cali o Medellín por parte de bandas armadas que mezclan mercenarios, policías y fuerzas militares, en un proceso bastante violento de encerramiento del espacio público, la transformación del paisaje urbanístico convertido en un espacio interior, asilado y protegido (Hernández, 2003, p. 70).

Asimismo, ciertos fenómenos económicos, como el neoliberalismo, y sociales, como el asesinato político, los atentados indiscriminados, el pillaje y la guerra por el dominio de mercados o bienes, en distintos niveles de intensidad, reemplazan los antiguos espacios de confrontación política y militar (Hernández, 2003, p. 70). Durante este período, según Hernández, el presidente conservador Belisario Betancur Cuartas (1982-1986) ofreció un proyecto de tregua y amnistía a las distintas agrupaciones armadas, consiguiendo que los grupos guerrilleros más activos de los primeros años de la década de los ochenta consolidaran un espacio político en las urbes: El M-19 establece, por su parte, distintas sedes en las ciudades, y las FARC, el Partido Comunista (PCC) y otros sectores de una izquierda progresista, construyen un proyecto político: La Unión Patriótica. Sin embargo,

Una extraordinaria máquina "diabólica" de guerra se ha desatado y, consolidándose como foco de atracción y subjetividad pública, desencadena el proceso genocida más aberrante que hayan sufrido las "terceras" fuerzas políticas del país (solamente de la UP, el número de muertos superó 3.000). El M-19 decide romper la tregua, se enfrenta a un gobierno impotente y unas fuerzas armadas "corruptas" y se toma el Palacio de Justicia en Bogotá (sede de la Corte Suprema de Justicia y del Consejo de Estado); el Ejército "reconquista" el edificio a sangre y fuego, masacrando por igual a magistrados, guerrilleros, litigantes y ciudadanos (Hernández, 2003, p. 70).

Durante los años noventa, el Gobierno firma acuerdos de paz, desarme $y$ reinserción social con algunas agrupaciones: El M-19, Quintín Lame, PRT (Partido Revolucionario de los Trabajadores), EPL y un sector minoritario del ELN (Corriente de renovación socialista) (Hernández, 2003, p. 71). De la misma manera, el Gobierno celebra encuentros de paz con otros grupos armados, los cuales fracasan. Y mientras tanto, 
El Estado multiplica su fuerza militar promoviendo y asegurando el desarrollo y la consolidación de fuerzas "no legales", como cuerpos especiales a medias creyentes a medias traidoras, pues no solo son un cuerpo adscrito, sino que con su impía violencia arrastran segmentos completos de la burocracia y la tecnocracia militar, a las que les imponen pactos que fisuran "el espíritu de cuerpo". Sin duda, la acción mercenario-nacionalista de los grupos paramilitares, los constituyen en una fuerza libre de ataduras jurídicas y legales, y por consiguiente apta para realizar acciones de saqueo, vandalismo, pillaje y saboteo, y sometidas a estos embates, la tierra y la renta, se redistribuyen y se reorganizan (Hernández, 2003, p. 73).

4. Las AUC negocian y se desmovilizan. El Estado empuja a las FARC a sus retaguardias (2005-2012). Durante el 2002, Álvaro Uribe prometió derrotar militarmente a las FARC con el apoyo de las Fuerzas Armadas. Se declaró la guerra contra el terrorismo y, por supuesto, contra los terroristas, clausurando así la posibilidad de diálogos y de negociación con la insurgencia. Uribe habló en nombre de la sociedad, sin ningún tipo de distinción, configurando, como ninguna otra autoridad en la historia del país, una sociedad de amigos en torno a un enemigo común: las FARC, a quienes prometió exterminar sin ninguna consideración, ni vacilación. Las FARC pasaron, entonces, a convertirse en el enemigo absoluto del país, que desprovistos de toda condición humana, política y jurídica, fueron combatidos mediante ciertas estrategias ideológicas y militares que alcanzaron una intensidad e inhumanidad insólitas. Este proceso de degradación de las FARC impidió, por supuesto, establecer una salida negociada al conflicto. En consecuencia, el exterminio, la desaparición, la mutilación, la tortura, la delación se constituyó en acciones lógicas de la paz como exterminio del enemigo. Esta forma de pacificación estatal implicó el total desconocimiento del opositor. Contrario al tratamiento jurídico-militar respecto a las FARC, Uribe impulsó el proceso de desmovilización de los paramilitares, a través de una serie de propuestas orientadas a la negoción en Ralito: Cese al fuego, el fin de los asesinatos y secuestros de civiles, rompimiento de los lazos con el negocio ilícito de la droga. En respuesta a la propuesta estatal, Carlos Castaño, el líder más claro de las Autodefensas Unidas de Colombia (AUC), afirmó que la organización era para-estatal, refiriéndose al apoyo de los paramilitares a la autoridad en su lucha contra la insurgencia. Posteriormente, el Gobierno Nacional obtuvo la aprobación del Congreso de la República de la "Ley de justicia y paz", permitiéndole el inicio de negociaciones con un grupo armado sin estatus político (AUC).

\section{REFERENCIAS}

Anrup, R. (2012). La nuda vita y la soberanía estatal. En Ángel, J. (Coord.). Aportes para una filosofía del sujeto, el derecho y el poder. Bogotá, Colombia: Universidad Libre. 
Carbó, E. (2009). El leguaje del presidente Uribe frente al terrorismo. Ideas para la paz. Recuperado de http://www.ideaspaz.org/articulos/download/42_el_ lenguaje_del_presidente.pdf

Castro, E. (2004). El vocabulario de Michel Foucault. Un recorrido alfabético por sus temas, conceptos y autores. Buenos Aires, Argentina: Prometeo Libros \& Universidad Nacional de Quilmes.

Castro, E. (2008). Giorgio Agamben. Una arqueología de la potencia. Buenos Aires, Argentina: Jorge Baudino Editores \& Universidad Nacional de General San Martín.

Centro Nacional de Memoria Histórica. (2013). ¡Basta ya! Colombia; Memorias de guerra y dignidad. Bogotá, Colombia: Imprenta Nacional.

Ferrajoli, L. (2007). El derecho penal del enemigo y la disolución del derecho penal IUS. Revista del Instituto de Ciencias Jurídicas de Puebla A.C., núm. 19. Instituto de Ciencias Jurídicas de Puebla A. C. Puebla, México

Galindo, A. (2005). Política y mesianismo. Madrid: España: Biblioteca Nueva.

Girard, R. (1983). La violencia y lo sagrado (J. Jordá, trad.). Barcelona, España: Anagrama.

Girard, R. (2002). La ruta antigua de los hombres perversos. (F. Diez del Corral, trad.). Barcelona, España: Anagrama.

González, F.E. (2014). Poder y violencia en Colombia. Bogotá, Colombia: OdeocofiCinep.

Hernández, E. (2003).Colombia: Paloma maquiavélica. Nómadas, (19), 66-75. Recuperado de http://www.redalyc.org/articulo.oa?id=105117940007

Lazzarato, M. (2007). La filosofía de la diferencia y el pensamiento menor. (G. Daza Navarrete, trad.). Bogotá, Colombia: Universidad Central, Instituto de Estudios Sociales Contemporáneos.

Metz, J. B. (1979). La fe, en la historia y la sociedad. Esbozo de una teología política fundamental para nuestro tiempo. (M. Olasagasti \& J. M. Bravo, trads.). Madrid, España: Cristiandad.

Metz, J. B. (1999). Por una cultura de la memoria. J.M. Ortega (trad.). Barcelona, España: Anthropos.

Mouffe. C. (2003). La paradoja democrática. T. Fernández \& B. Eguibar (trads.). Barcelona, España: Gedisa.

Nancy, J.L. (1983). L’Impératif catégorique. Paris, France: Flammarion.

Nancy, J.L. (1996). La existencia exiliada. (J. López Guix, trad.). Archipiélago. Cuadernos de crítica de la cultura, (26-27), 34-39.

Ruiz, A. \& Londoño, L.M. (2010). Desde diversas Orillas. Medellín, Colombia: Universidad de Antioquia, Instituto de Estudios Regionales \& Centro Internacional de Investigaciones para el Desarrollo (IDRC). 
Ruiz, A., \& Mesa, J. (2013). Consideraciones sobre el enemigo público en Colombia: 1998-2009. Boletín de Antropología, 28(45), 40-61.

Semana. (2010). Las FARC buscan justificar el asesinato del gobernador del Caquetá: Uribe. Revista Semana. Recuperado de http://www.semana.com/nacion/ conflicto-armado/articulo/las-farc-buscan-justificar-asesinato-del-gobernadordel-caqueta-uribe/111667-3

Sofsky, W. (2006). Tratado sobre la violencia. J. Chamorro Mielke (trad.). Madrid, España: Abada.

Uribe, M.T. (2004). Antropología de la inhumanidad. Un ensayo interpretativo sobre el terror en Colombia. Bogotá, Colombia: Grupo Editorial Norma.

Uribe de H., M.T. (2005). Nación, ciudadano y soberano. Medellín, Colombia: Corporación Región. 